\title{
Correction to: It Is the Little Things That Matter
}

\author{
Elizabeth Louise O'Riordan, MBChB, FRCS, PhD, PGDip (Oncoplastic Surgery)
}

West Suffolk Hospital, Bury St Edmunds, Suffolk, England

\section{CORRECTION TO: ANN SURG ONCOL HTTPS://DOI.ORG/10.1245/S10434-021-10498-W}

The author's affiliation is correct as reflected here. The original article was corrected.
Publisher's Note Springer Nature remains neutral with regard to jurisdictional claims in published maps and institutional affiliations.

The original article can be found online at https://doi.org/10.1245/ s10434-021-10498-w.

(C) Society of Surgical Oncology 2021

Published Online: 6 August 2021

E. L. O'Riordan, MBChB, FRCS, PhD, PGDip

(Oncoplastic Surgery)

e-mail: liz@oriordan.co.uk 